This item was submitted to Loughborough's Research Repository by the author.

Items in Figshare are protected by copyright, with all rights reserved, unless otherwise indicated.

\title{
Enhancing skills of academic researchers: the development of a participatory threefold peer learning model
}

PLEASE CITE THE PUBLISHED VERSION

https://doi.org/10.1080/14703297.2018.1505538

\section{PUBLISHER}

(C) Taylor \& Francis (Routledge)

\section{VERSION}

AM (Accepted Manuscript)

\section{PUBLISHER STATEMENT}

This is an Accepted Manuscript of an article published by Taylor \& Francis in Innovations in Education and Teaching International on 24 August 2018, available online:

http://www.tandfonline.com/10.1080/14703297.2018.1505538.

\section{LICENCE}

CC BY-NC-ND 4.0

\section{REPOSITORY RECORD}

Barnard, Sarah, Becky Mallaband, and Kerstin Leder Mackley. 2018. "Enhancing Skills of Academic Researchers: The Development of a Participatory Threefold Peer Learning Model”. figshare. https://hdl.handle.net/2134/34658. 


\title{
Enhancing skills of academic researchers: the development of a participatory threefold peer learning model
}

\author{
Sarah Barnard ${ }^{\mathrm{a} *}$ Becky Mallaband ${ }^{\mathrm{b}}$ and Kerstin Leder Mackley ${ }^{\mathrm{c}}$ \\ ${ }^{a}$ School of Business and Economics, Loughborough University, UK \\ ${ }^{b}$ School of Engineering \& Applied Science, Aston University, Birmingham, UK \\ ${ }^{c} U C L$ Knowledge Lab, Institute of Education, University College London, London, UK
}

Provide full correspondence details here including e-mail for the *corresponding author:

Dr Sarah Barnard, School of Business and Economics, Loughborough University.

S.H.Barnard@lboro.ac.uk

Word count: 4975

Provide short biographical notes on all contributors here if the journal requires them.

Sarah Barnard is Lecturer in Sociology of Contemporary Work in the School of Business and Economics at Loughborough University. Sarah’s fields of research include organisations, gender, higher education, sociology of science, engineering and technology and communications. She is currently Principal Investigator for three research projects: a longitudinal study of women in higher education institutions, a project on LGBT workers in the construction sector and 'Communities of Practice for Accelerating Gender Equality and Institutional Change in Research and Innovation across Europe'.

Becky Mallaband is a lecturer in Product Design in the School of Engineering and Applied Science at Aston University. Her research focuses on User Centred Design (UCD), particularly within the domestic energy domain. She is particularly interested in how a UCD approach can be used within interdisciplinary research and how it can add value to the engineering design process of energy saving technologies. She has worked on multidisciplinary projects with other academic institutes, commercial and industrial partners, including the RCUK/E.ON funded project CALEBRE (Consumer Appealing Low Energy Building Retrofitting) and the EPSRC DEFACTO project (Digital Energy Feedback and Control Technology Optimisation).

Kerstin Leder Mackley is a Senior Research Associate at the UCL Knowledge Lab, currently exploring the social meanings and significance of digital touch technologies and their impact on 
communication (in-touch-digital.com). Her research interests include the sensory and visual ethnographic exploration of (digital) media in people's lives. She has ten years of postdoctoral research experience across three higher education institutions, having previously contributed to interdisciplinary projects at the School of Engineering and Design, Brunel University, the Department of Social Sciences, Loughborough University, and the Loughborough Design School. 


\title{
Enhancing skills of academic researchers: the development of a participatory threefold peer learning model
}

\begin{abstract}
In this article, we introduce a threefold peer learning model developed during the design and implementation of an innovative researcher-led digital skills training programme for early career researchers. The programme brought together researchers from three UK universities and facilitated the personal and professional development of: (1) the researchers who organised the programme; (2) the researchers who designed and delivered content; and (3) the researchers who attended and participated in the digital skills workshops. This article outlines and reflects on its participatory approach to collaborative learning, which responded to the changing needs of UK higher education researchers who increasingly find themselves in interdisciplinary and digitally mediated research contexts. Finally, we propose the transferability of the approach to other fields of knowledge, student/staff learning and professional development.
\end{abstract}

Keywords: early career researchers (ECRs); peer learning; communities of practice; higher education institutions; staff development

\section{Introduction}

Across UK Higher Education Institutions (HEIs), there has been an increase in funding by the Research Councils UK (2017) for digital economy projects which investigate the possible impact of digital technologies on community life, cultural experiences, future society, and the economy. These projects seek to develop digital technologies and techniques, creating new opportunities for academic research (Kaplan \& Haenlein, 2010; Buzzard et al. 2011), large-scale impact within and beyond academia and enhancing interdisciplinary working (Vincent-Lancrin, 2006). For Early Career Researchers (ECRs), these projects demand new, specialist and creative skills that often go beyond subject-specific research tasks, including for example: visualisation and communication of data sets; the design of digital applications; the management of audio-visual data; the creation of publicity materials; or the development and 
maintenance of a web presence. Whilst digital skills training can form part of staff development, such courses are often generic and fall short of addressing the specific needs of researchers. Instead ECRs are regularly required to teach themselves by trialand-error or learn through informal peer-exchange in established research groups and academic communities.

In this article, we reflect on a peer-to-peer skills exchange programme which sought to fill this gap and build on existing strengths, knowledge and skills amongst digitally-active research staff to educate peers across different disciplines and HEIs. The main focus of this paper is to theorise the programme as an example of continued professional development (CPD) that goes beyond the concept of peer-assisted learning and fosters a threefold peer learning model, within a Community of Practice (CoP), positioning ECRs as workshop attendees, trainers, and organisers. Whilst centred on the specific needs of research staff, the threefold peer learning model is relevant and applicable beyond the immediate context of the scheme.

\section{The 'Design and the Digital World' programme}

'Design and the Digital World' (DDW), funded by an AHRC Training Grant, ran from June 2014 until October 2015. DDW aimed to address knowledge gaps in digital skills amongst researchers in three Midlands universities, drawing on the digital expertise of research staff from a range of backgrounds. These included arts-based disciplines, like design and media studies, but also extended to human-computer interaction and engineering.

A 5-person cross-institutional organising team initially designed and circulated a mixed-method questionnaire to research staff $(n=205)$ within each of the partner institutions to identify both digital skills gaps and areas of expertise. The questionnaire 
also asked respondents to signal their willingness to volunteer their time to teach sessions, which resulted in involvement of sixteen trainers (and two organisers).

The design and analysis of the questionnaire specifically sought to explore and situate relevant contexts of digital skills' use, in parts through open questions. A nalysis of responses resulted in four topics for individual workshops: establishing a digital presence; communicating research processes and ideas; creatively organising and visualising data; and increasing your digital impact. The sessions were designed to follow the different stages of the research process, from participant recruitment and project branding to the dissemination of findings, addressing the creative use of individual digital tools and software in the process.

To achieve this, the trainers collaborated with organisers in workshop teams to produce materials and facilitate workshops across the three institutions.

\section{Early career researchers as 'unique’ learners}

ECRs are members of university staff whose central duties focus on conducting research and who are at the early stages of their academic 'research' careers. The AHRC (2015) defines ECRs as within eight years of a PhD award (or equivalent professional training) or within six years of their first academic position. Whilst this may include (senior) lecturers who have not long embarked on a research trajectory, the roles that most commonly fall into this category in the UK include Research Assistant, Research Associate, and Research Fellow. ECRs are often employed on fixed-term, rather than permanent contracts, primarily through external funding, and they constitute a diverse group, with varying levels of professional and academic experience. Likewise, individuals' job roles differ; some ECRs have teaching and administrative workloads in addition to research, and the level of responsibility for intellectual development and project management is partly dependent on the working practices of individual Principal 
Investigators.

ECRs have a unique position within academic institutions, as they have begun to develop a professional profile and expertise through doctoral studies and other academic experience, but are still situated, by definition, in the early stages of their academic research careers. Some aspects of ECRs' training needs overlap with those of research students, some with academic staff. The skills exchange programme presented here emerged out of the recognition that certain changes in the academic landscape had specifically impacted on the role of research staff, as well as on their career trajectories, and that generic CPD did not always take these changes into account. Changes include larger-scale, multi-disciplinary research projects, often in the realm of the digital economy, the potential for digital data collection (Hookway, 2008; Murthy, 2008) and the need to maintain a research profile (at an individual and project level) in the face of growing job insecurity (Watkinson et al., 2017). Furthermore, innovations in communication technologies have required ongoing training and updating over the course of a professional career.

At the outset, ECRs may not necessarily consider themselves part of a community, not least as they work in different disciplines and domains. While institutional initiatives bring together researchers for instances of shared learning, these often happen in isolation and may not in themselves aid a sense of community or cohesion. In the context of this scheme, DDW's participatory approach and the ECRs' active role in collectively shaping the programme design and content put into place processes and a sense of ownership that could be meaningfully approached as giving rise to a 'Community of Practice'. We first detail the threefold learning model at the core of the scheme, before reflecting on what might be gained by theorising it in relation to the concept of CoP. 


\section{The threefold learning model: The development of a learning approach through practice}

The threefold model of peer-learning that resulted from the DDW approach engaged ECRs in three different learner roles: attendees, trainers and organisers. Peer learning such as that harnessed in the DDW programme offers opportunities to develop learning environments that recognise both the situated nature of learning and depends on the evolving participation of students in knowledge production (Hilsdon, 2014). Through its approach, DDW provided personal and professional development for all parties involved, and enabled collaborative knowledge exchange based upon concepts of mutuality. In the following, we discuss in more detail how ECRs on the programme took on the three different guises of the learner role.

\section{ECR as attendee}

The first goal of the programme was to enhance the skills and professional development of the workshop attendees of which there were 80 in total (with some attending more than one workshop). Through the interactive nature of the sessions, these stakeholders were invited to be 'active learners' (Warhurst, 2008), developing skills, furthering professional development and applying ideas to their own work. Activities, for instance, included turning one’s research topics into short video stories, thus developing a mini narrative that directly engaged with ECRs’ own research and materials; and taking text from a piece of research writing and turning it into a word cloud. Bringing varying levels of digital expertise to the workshops, attendees worked in groups to inform each other's approaches. The structure of the sessions meant that organisers and trainers also became active participants when they were not delivering content, often taking on board insights from both fellow trainers/organisers and attendees. This broke down the traditional teacher-learner binary and resulted in a sense of mutual collaborative 
support.

Attendee feedback was collected at the end of each session: formally through workshop evaluation forms and informally in conversations with the organisers. Feedback from the first of each session was used to improve or adapt the workshop content for subsequent repeats and future workshops. Whilst it was not within the scope of the scheme to assess impact of the programme in the longer term, the initial feedback highlighted the value of mutual (and potentially ongoing) support and the bespoke character of the sessions. Attendees commented that it was 'good to hear about different people's experiences in the digital world and see how others have used technology'; they felt 'more confident to use some tools', that it was good to be able to ask questions specific to their own research projects. They also talked about making positive changes to their own research profile, for example: '[I] resolve to be more active on Twitter [and to] think about strategy - especially for promoting publications'. Moreover, attendees reported a desire to 'further develop the relationship between design and research through contacts met during [the] workshop' and to 'look into participating in a working group to enable use of digital tools for recruiting participants in research'.

\section{ECR as trainer}

The programme intended to provide ECRs acting as a trainer with the chance to practice and enhance their teaching, presentation and communication skills in a supportive and relatively 'low risk’ environment. This opportunity was deemed important given increasing competition for lecturing contracts (Ellis et al., 2014; Vitae, 2017), which is often the next career move for ECRs (Åkerlind, 2008). Trainers joined organisers in pre-workshop planning meetings to jointly begin the process of planning, before preparing their own materials, giving them valuable lesson preparation experience. They were then asked to share their plans with the organising team and fellow trainers, 
giving them opportunity to learn through feedback (Boud et al., 1999). The workshops involved the trainers facilitating more traditional 'teaching' moments, as well as taking on the role of mentors in responding to individuals' needs during interactive sections. In the process, trainers reflected on and recounted their own research practices. The teamtaught approach allowed for a range of approaches to be heard, enabled collaboration and enhanced support for trainers; a wider variety of teaching styles for attendees; and allowed a greater number of trainers to participate. While the pre-workshop meetings were crucial to achieving a dialogue between and within sessions, they also allowed trainers and organisers to recognise and, in turn, emphasise emerging themes. One example of this was the importance of using a range of digital tools in combination in order to publicise research and build professional and project profiles. This was closely linked to the idea of developing a digital strategy for disseminating findings.

Like workshop attendees, trainers were asked to reflect on their experience of the scheme: one trainer reflected on the collaboration and exchange that also built a sense of community:

'All of us are working on our own research projects. We learn to use digital technologies as and when we need them - and it's often a frustrating and lonely process. I joined the DDW team because I wanted to share the skills I had acquired but also because I wanted to see what tools other academics were using and how I could incorporate them in my own work. None of us are experts in digital technologies but collectively we have expertise and DDW was a means to leverage that.'

Whilst others were more specific about practical ways in which the experience had been beneficial: 'The experience as a trainer led me to rethink the kind of images I use and to emphasise more how I present numerical data.' 


\section{ECR as organiser}

There was a small team of ECRs who initiated, organised and secured the funding for DDW, and who were all supported by their individual institutions' research staff associations. This team benefitted from a broad range of practices, beginning with development of the successful grant application, but extending to project management skills; communication and marketing skills to advertise the programme; finance skills to manage the budget; and time management skills, all of which are important for professional career development (Vitae, 2017). In addition to the skills questionnaire, interactions between organisers and trainers during the topic-specific project meetings were an important starting point for planning. In these meetings, organisers helped to build bridges between trainers, structure sessions to safeguard overall coherence, and maximise opportunities for attendees to practice skills in hands-on workshop activities. Organisers were also active participants and, at times, trainers in the individual workshops. The table below indicates the different roles played at different stages by ECRs during the programme.

[Table 1 around here]

Some of the skills needed by the programme organisers can be directly applied to future principal investigator and co-investigator roles as well as academic research, module or programme leadership (Vitae, 2017). For the ECRs involved, this was the first grant held in their name and, as such, the project represented an academic 'rite of passage' ${ }^{1}$.

\footnotetext{
${ }^{1}$ Evidencing this, the three authors have successfully made the next career step since the project ended - two are now lecturers, the other a senior research associate.
} 
Figure 1 shows the quasi-accumulative skills development possible through the different roles that ECRs adopted in the programme: the threefold peer learning model.

[Figure 1 around here]

\section{Establishing a community of practice within the threefold learning model}

Sociocultural theories of learning and the notion of social learning systems suggest that knowledge and skills acquisition is shaped by the social context, culture, and tools that form part of a given learning situation (Kolb, 2014). They tend to locate learning 'not in the head or outside it, but in the relationship between the person and the world, which for human beings is a social person in a social world', in a 'relation of participation' (Wenger 2010: 179). A central concept in sociocultural approaches to learning is that of ‘Communities of Practice’ (Lave \& Wenger, 1991; Wenger, 2000) which has been applied in studies of innovation in ICT in education, amongst other areas (see Schlager et al., 2002; Yang, 2009). CoP as a concept is particularly relevant in the context of DDW as it clearly locates identity work, knowledge formation and learning more broadly within communities (Duguid, 2005; see also Stark et al., 2016).

As opposed to traditional 'top-down' models of training, which are instigated, designed and carried out by more senior staff or specific staff development teams, the DDW programme focussed on a bottom-up, participatory approach throughout. De Laat et al. (2014) highlight the need for learners to become 'architects of their own professional learning spaces', as the ECRs did in this programme. Organisers shaped, facilitated and built on the contributions of trainers, ultimately learning how to give the scheme focus and coherence in the process, and both trainers and attendees shared their own professional experiences, thus contributing to active learning. For example, early feedback suggested that the ECRs needed more time for hands-on activities and 
'surgery' time with the trainers, which was taken into account in later sessions, when more time was allocated to these kinds of activities.

While certain hierarchies could not be wholly avoided, we do not see the organisers' strategic roles or the trainers' instances of 'imparting' knowledge and expertise as at odds with CoPs as it is argued that learning through CoPs is enhanced through meaningful interactions between those more or less knowledgeable or 'expert' (Barnard et al., 2016). Indeed, the ‘situated learning’ (Lave \& Wenger, 1991) approach went beyond what was achieved in individual workshops to also implicate individual researchers' identities and professional profiles in the longer term. This was enhanced through the crucial networking opportunities the sessions provided within and across higher education institutions, which in turn assisted in the constitution of the ECRcommunity over and above disciplinary or institutional contexts as individual researchers made links around shared interests and stayed connected after the programme of workshops had ended.

\section{Reflections on challenges and opportunities}

Motivation to participate in the programme was enhanced through the threefold peer learning model as ECRs could participate in a way that suited their interests, skills and aspirations, having the opportunity to benefit their own development, and that of others. Networking across differing institutions also represented an incentive to trainers and attendees, as did the cross-disciplinary nature of the scheme which aided a deeper sense of reflection amongst ECRs as regards the successful communication of ideas and techniques. Informal and formal feedback indicated that the scheme benefitted from organisers and trainers as peer 'teacher practitioners', as attendees felt a direct relationship to the 'real-life' case studies discussed. None of this is to say that this approach is the only way forward in CPD, but that specific learning communities, such 
as ECRs, may particularly benefit from community-led activities. Whilst all the trainers had digital knowledge and expertise, their experience in teaching varied significantly: some had many years' experience lecturing and others were new to the role. Trainers were given many chances to discuss their ideas for how their part might work in practiceand peer feedback was encouraged. Similarly workshop attendees were aware of the professional development aspect for the trainers themselves, and constructive feedback was encouraged and collected in the sessions. The trainers with the least prior experience of teaching made the most of this opportunity to 'learn by doing' (Kolb, 2014), to gain support and ideas from fellow ECRs and receive feedback in a relatively 'safe' context.

Some of the key challenges of the scheme related to the recruitment of trainers on topics that ECRs had expressed an interest in, and the time spent planning, organising and delivering sessions. The majority of trainers were on research-only, fixed-term contracts, and whilst it was anticipated that individual researchers would be able to contribute to the programme as part of the allowed 6 hours a week of professional development time, in practice, few of the researchers were actually able to take advantage of this and instead prepared in their own time. This added a significant time burden for contributing staff, a common constraint in workplace learning activities (Lohman, 2009). While there was some notional administrative support within the grant holder's department and broader support from professional development staff, it wasn't always clear how this could be accessed, and both trainers and organisers reflected on the need for all the institutions involved to play a more active role in programme administration and facilitating collaboration. The programme running across three universities added more complexity to the organisation of the workshops; recruitment and session preparation practicalities were hampered by differences in, or a lack of, 
established and effective communication channels, or unfamiliarity with facilities. Our reflection has been that an institutional facilitating role is needed to support, rather than replace, that of the ECR organising team to maintain the community-driven approach. Trainer recruitment and programme publicity were most successful where there was support from senior management, professional development colleagues and established institutional networks (e.g. the research staff associations). Whilst in the context discussed in this paper, the implementation of a threefold learning approach places a burden on more junior staff, the benefits of such integration and organisation are clear and significant.

\section{Conclusions}

In this article, we have illustrated how formal learning programmes can be adapted to maximise the scope of development for those involved. Here the focus has been on ECRs in HEIs, who we have argued present a unique opportunity and challenge for community-led peer learning. Involvement as an organiser or trainer in this programme represented the opportunity to autonomously evidence teaching experience, strengthen networks and gain recognition from those more senior in the institution for receiving external funding and successfully completing the project. Therefore, we argue that peer learning programmes like the one described here offer an important opportunity for academic identity formation (see also Boud, 1999) through CoP.

The threefold peer learning model harnesses peer-learning within a community of practice approach to maximise the development opportunities for everyone involved and could be applied in other sectors or organisational settings that have already tried to develop communities of practice or a peer assisted learning (PAL) programme. In doing so, it is crucial to involve the community of learners in the conceptualisation, 
organisation and design of a training programme from the outset, as has been demonstrated in DDW.

The idea of a 'bottom-up' model for training is potentially attractive to those institutions or organisations wishing to transfer the task of career development to employees (Lips-Wiersma \& Hall, 2007). However, as discussed, this also includes the danger of placing too much responsibility on those relatively junior and contractually vulnerable positions such as ECRs. Therefore, the ideal is not that the responsibility is wholly transferred to individuals, rather developed in collaboration with existing communities and networks active in that arena. The emphasis of ECRs as a community should not be overlooked in the sense that an academic identity is traditionally built upon notions of collegiality and the sense of an academic community (Henkel, 2005). This threefold peer learning model, which strongly supports and encourages the collaboration between early career researchers, actively discourages the 'social isolation' often encountered in academic institutions. The participatory approach outlined is not straightforward to apply in practice. Taking into account the needs and wishes of multiple stakeholders is complex, but is to be expected and welcomed as evidence of active participation of the community involved. Furthermore, where there is strong motivation to participate and learn, the incorporation of a threefold peer learning model can be a powerful development tool. In a profession where there is a low level of control (Waaijer et al., 2016), placing training opportunities within the control of those who need them is a positive step forward.

\section{Acknowledgements}

The authors would like to thank all trainers and attendees who contributed to Design and the Digital World. Special thanks to our co-organisers, Sarah Martindale (University of Nottingham) and Martin Sterry (University of Leicester), and those who supported the scheme 
at Loughborough University and Vitae. This work was supported by the Arts and Humanities Research Council [grant number AH/L010844/1].

\section{References}

Åkerlind, G. S. (2008). Growing and developing as a university researcher. Higher Education, 55(2), 241-254. http://doi.org/10.1007/s10734-007-9052-x

Barnard, S. Hassan, T., Dainty, A. Polo, L. \& Arrizabalaga, E. (2016) ‘Using communities of practice to support the implementation of gender equality plans: lessons from a cross-national action research project', Paper presented at the GenderTime Conference, Paris, 29-30 September 2016.

Boud, D. (1999) 'Situating academic development in professional work: Using peer learning', International Journal for Academic Development, 4:1, 3-10, DOI: 10.1080/1360144990040102

Boud, D., Cohen, R., \& Sampson, J. (1999). 'Peer learning and assessment. Assessment \& Evaluation in Higher Education, 24(4), 413-426.

Buzzard, C., Crittenden, V.L., Crittenden, W.F. and McCarty, P. (2011). The use of digital technologies in the classroom: A teaching and learning perspective. Journal of Marketing Education, 33(2), pp.131-139.

De Laat, M., Schreurs, B. and Sie, R. (2014). Utilizing informal teacher professional development networks using the network awareness tool. The architecture of productive learning networks, p.239.

Duguid, P. (2005). “The art of knowing”: Social and tacit dimensions of knowledge and the limits of the community of practice. Information Society, 21(2), 109-118. http://doi.org/10.1080/01972240590925311

Ellis, V., McNicholl, J., Blake, A., \& McNally, J. (2014). Academic work and proletarianisation: A study of higher education-based teacher educators. Teaching and Teacher Education, 40, 33-43. http://doi.org/10.1016/j.tate.2014.01.008

Henkel, M. (2005). Academic identity and autonomy in a changing policy environment. Higher Education, 49(1-2), 155-176. http://doi.org/10.1007/s10734-004-2919-1 Higher Education Academy (2011) The UK Professional Standards Framework for Teaching and Supporting Learning in Higher Education. The Higher Education Academy, Guild HE, Universities UK. 
Hilsdon, J. (2014). Peer learning for change in higher education. Innovations in Education and Teaching International, 51(3), 244-254. http://doi.org/10.1080/14703297.2013.796709

Hookway, N. (2008). ‘Entering the blogosphere’: some strategies for using blogs in social research. Qualitative Research, 8(1), 91-113. http://doi.org/10.1177/1468794107085298

Kaplan, A.M. and Haenlein, M., (2010). Users of the world, unite! The challenges and opportunities of Social Media. Business horizons, 53(1), pp.59-68.

Kolb, D. A. (2014). Experiential learning: Experience as the source of learning and development. FT press.

Lave, J., \& Wenger, E. (1991). Situated Learning: Legitimate Peripheral Participation. Cambridge: Cambridge University Press.

Lips-Wiersma, M., \& Douglas, T. H. (2007). Organizational career development is not dead: a case study on managing the new career during organizational change. Journal of Organizational Behavior, 28, 771-792. http://doi.org/10.1002/job

Lohman, M. (2009). A Survey of factors influencing the engagement of information technology professionals in informal learning activities. Information Technology, Learning \& Performance Journal, 25(1), 43-54. http://doi.org/10.1002/hrdq.1153

Murthy, D. (2008). Digital Ethnography: An Examination of the Use of New Technologies for Social Research. Sociology, 42(5), 837-855. http://doi.org/http://dx.doi.org/10.1177/0038038508094565

Research Councils UK (2017) Digital Economy. Available at: http://www.rcuk.ac.uk/research/xrcprogrammes/Digital/ Accessed 1st August 2017.

Schlager, M., Fusco, J., \& Schank, P. (2002). Evolution of an online education community of practice. Building virtual communities: Learning and change in cyberspace, 129, 158.

Stark, A. M., \& Smith, G. A. (2016). Communities of practice as agents of future faculty development. The Journal of Faculty Development, 30(2), 59-67.

Vincent-Lancrin, S. (2006). What is changing in academic research? Trends and futures scenarios. European Journal of Education, 41(2), pp.169-202. 
Vitae (2017) Concordat to Support the Career Development of Researchers. Available at: https://www.vitae.ac.uk/policy/concordat-to-support-the-career-developmentof-researchers/strategy-researcher-development-and-careers. Accessed $8^{\text {th }}$ August 2017.

Waaijer, C. J. F., Belder, R., Sonneveld, H., van Bochove, C. A., \& van der Weijden, I. C. M. (2016). Temporary contracts: effect on job satisfaction and personal lives of recent PhD graduates. Higher Education. http://doi.org/10.1007/s10734-0160050-8

Warhurst, R. P. (2008). 'Cigars on the flight-deck’: new lecturers’ participatory learning within workplace communities of practice. Studies in Higher Education, 33(4), 453-467.Watkinson, N. D., A., Boukacem-Zeghmouri, C., Rodríguez-Bravo, B., Xu, J., Abrizah, A., \& Herman, E. (2017). Early career researchers: Scholarly behaviour and the prospect of change. Learned Publishing, 30(2), 157-166.

Wenger, E. (1998). 'Communities of practice: learning, meaning, and identity'. Cambridge: Cambridge University Press.

Wenger, E. (2000). Communities of Practice and Social Learning Systems. Organization, 7(2), 225-246.

Wenger, E. (2010). Conceptual Tools for CoPs as Social Learning Systems: Boundaries, Identity, Trajectories and Participation. In Chris Blackmore (ed), Social Learning Systems and Communities of Practice. London, Springer: 125-143. Yang, S.-H. (2009). Using Blogs to Enhance Critical Reflection and Community of Practice. Journal of Educational Technology \& Society, 12(2), 11-21. 
Table 1. Activities of organisers, trainers and attendees.

\begin{tabular}{|c|c|c|c|c|}
\hline Task & Approach & Organisers & Trainers & Attendees \\
\hline $\begin{array}{l}\text { 1. Plan and disseminate } \\
\text { digital skills survey }\end{array}$ & $\begin{array}{l}\text { Questionnaire to identify expertise and } \\
\text { skills requirements by ECRs }\end{array}$ & $\checkmark$ & & \\
\hline $\begin{array}{l}\text { 2. Kick-off and overall } \\
\text { programme planning }\end{array}$ & $\begin{array}{l}\text { Workshop meeting drawing on } \\
\text { questionnaire results }\end{array}$ & $\checkmark$ & & \\
\hline $\begin{array}{l}\text { 2. Invite ECRs to be } \\
\text { trainers }\end{array}$ & $\begin{array}{l}\text { Using results of the questionnaire the } \\
\text { organisers approached possible trainers }\end{array}$ & $\checkmark$ & & \\
\hline $\begin{array}{l}\text { 3. Session planning } \\
\text { meeting }\end{array}$ & $\begin{array}{l}\text { Workshop to discuss session content } \\
\text { and approach }\end{array}$ & $\checkmark$ & $\checkmark$ & \\
\hline 4. Content development & $\begin{array}{l}\text { Individual trainers developing content } \\
\text { and sharing with group for feedback }\end{array}$ & $\checkmark$ & $\checkmark$ & \\
\hline $\begin{array}{l}\text { 5. Final session planning } \\
\text { meeting }\end{array}$ & Meeting to finalise the session plans & $\checkmark$ & $\checkmark$ & \\
\hline 6. Session delivered & $\begin{array}{l}\text { Each session is delivered twice, once at } \\
\text { Loughborough University and once at } \\
\text { another East Midlands university }\end{array}$ & $\checkmark$ & $\checkmark$ & $\checkmark$ \\
\hline 7. Session evaluation & $\begin{array}{l}\text { Feedback questionnaire from session } \\
\text { attendees }\end{array}$ & $\checkmark$ & $\checkmark$ & $\checkmark$ \\
\hline $\begin{array}{l}\text { 8. Programme } \\
\text { evaluation meeting }\end{array}$ & $\begin{array}{l}\text { Workshop to discuss how the } \\
\text { programme went and for the trainers } \\
\text { and organizers to share their } \\
\text { experiences }\end{array}$ & $\checkmark$ & $\checkmark$ & \\
\hline
\end{tabular}


Figure 1. Threefold Peer Learning Model.

Threefold Peer Learning Model

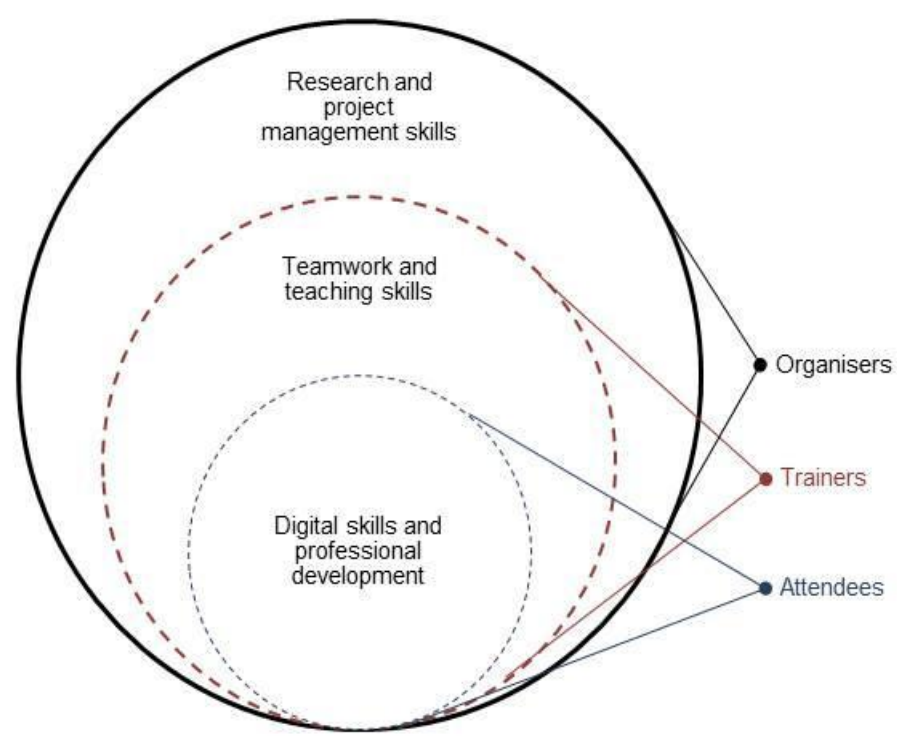

